\title{
Laparoscopically guided percutaneous choledochoscopy: minimally invasive interdisciplinary rendezvous for selected patients
}

During laparoscopic cholecystectomy, unexpected findings may mandate immediate intraluminal biliary visualization for safe patient management. We evaluated percutaneous cholangioscopy in two whole-body donors.

After preparation of the hilus, the sterile, single-use, $11 \mathrm{Fr}$, single-operator cholangioscope, with working channels for guidewire (or instruments) and irrigation (SpyGlass DS; Boston Scientific, Ratingen, Germany), was advanced through one of the trocars from the right lateral flank ( Fig.1a). Intra-abdominal navigation toward the biliary entry site (cystic duct or choledochotomy) was achieved through a combination of trocar guidance, laparoscopic forceps, and the endoscope hand wheels ( $\triangleright$ Fig. $\mathbf{1}$ b, $\triangleright$ Video $\mathbf{1}$ ). Wire insertion from the cholangioscope into the entry site facilitated navigation. Intraoperative visualization was mimicked by access through the cystic duct

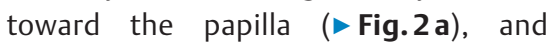
through the choledochotomy toward the papilla, and across the hilus to the segmental branchings ( $\mathbf{F i g . 2} \mathbf{b}$ ). In one case, a thin cystic duct did not allow entry of the cholangioscope, so choledochotomy was performed. In the other donor, although vision was blurred by postmortem-thickened bile, small stones could be flushed out of the common bile duct (CBD), indicating that cholangioscopy was able to provide basic therapy. No fluoroscopy control was needed. Choledochoscopy was available within 5 minutes from opening the biliary access site. Access sites were closed by single-button sutures (choledochotomy) or two titanium clips (cystic duct).

Laparoscopically guided choledochoscopy provides a fast, simple, sterile, and radiation-free method for direct intraoperative visualization of the biliary ducts. Although our data are still preliminary, this single-step, laparoscopic-endoscopic rendezvous may allow a minimally invasive, interdisciplinary strategy
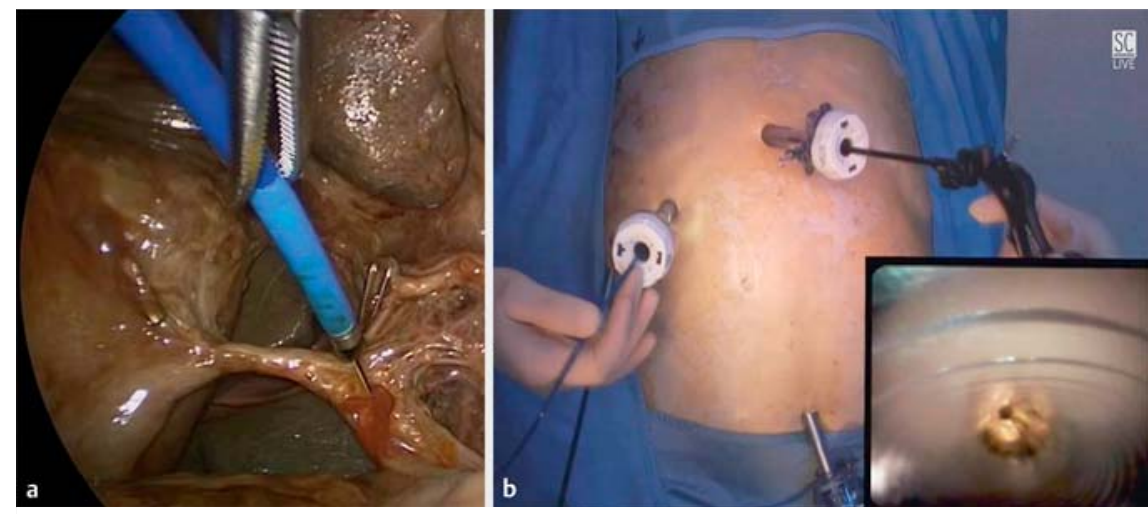

- Fig. 1 Percutaneous choledochoscopy. a The cholangioscope was manually advanced through the trocar on the right side; the inset shows the cholangioscopic view within the trocar. $\mathbf{b}$ The cholangioscope was maneuvered through the inflated abdominal cavity by a combination of laparoscopic forceps guidance, endoscopic hand wheels, and wire guidance.

for selected patients. Possible indications include: 1) laparoscopic-endoscopic CBD stone clearance after failed endoscopic removal or intraoperatively identified CBD stones [1,2]; 2) laparoscopic CBD closure without T-tube after ensuring CBD integrity endoscopically via the cystic duct and, if necessary, simultaneous sphincterotomy [3-5]; and 3) management of unexpected Mirizzi syndrome with stone penetration.
Endoscopy_UCTN_Code_TTT_1AT_2AB

\section{Competing interests}

The cholangioscopes (SpyGlass DS) were provided by Boston-Scientific, Ratingen, Germany. Dr. Goetz is a consultant for Boston Scientific.

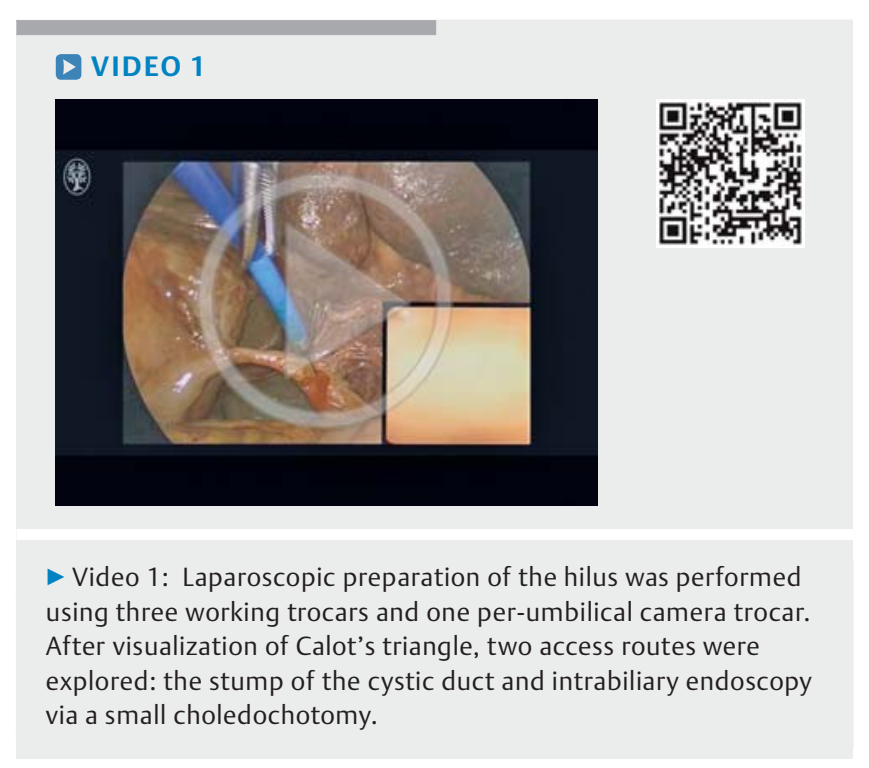



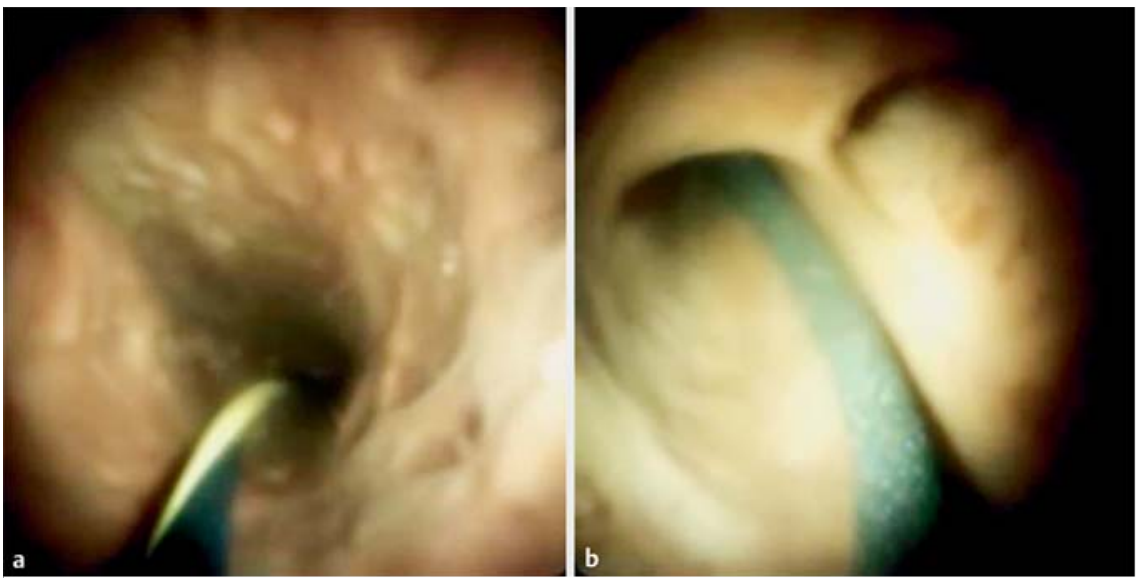

- Fig. 2 Intraoperative visualization during percutaneous choledochoscopy. a Cholangioscopic view of wire-guided advancement into the distal common bile duct from a proximal entry site. $\mathbf{b}$ Left liver segmental ducts.

The Authors

Marty Zdichavsky ${ }^{1}$, Bernhard Hirt ${ }^{2}$, Andreas Kramer $^{2}$, Alfred Königsrainer ${ }^{1}$, Nisar P.

Malek $^{3}$, Ulrich Schweizer ${ }^{1}$, Martin Goetz ${ }^{3}$

1 Allgemeine, Viszeral- und

Transplantationschirurgie,

Universitätsklinikum Tübingen, Tübingen

2 Institut für Klinische Anatomie und Zellanalytik, Dept. für Anatomie, Eberhard Karls Universität Tübingen, Tübingen

3 Innere Medizin 1, Universitätsklinikum Tübingen, Tübingen

\section{References}

[1] Jinfeng Z, Yin Y, Chi Z et al. Management of impacted common bile duct stones during a laparoscopic procedure: a retrospective cohort study of 377 consecutive patients. Int J Surg 2016; 32: 1 - 5

[2] Petelin JB. Laparoscopic common bile duct exploration. Surg Endosc 2003; 17: $1705-$ 1715

[3] Gupta N. Role of laparoscopic common bile duct exploration in the management of choledocholithiasis. World J Gastrointest Surg 2016; 8: $376-381$

[4] Topal B, Aerts R, Penninckx F. Laparoscopic common bile duct stone clearance with flexible choledochoscopy. Surg Endosc 2007; 21: 2317-2321

[5] Savita KS, Bhartia VK. Laparoscopic CBD exploration. Indian J Surg 2010; 72: 395-399

\section{Bibliography}

DOI http://dx.doi.org/10.1055/s-0042-121487

Endoscopy 2017; 49: E29-E30

(c) Georg Thieme Verlag KG

Stuttgart · New York

ISSN 0013-726X
Interdisciplinary Endoscopy, Innere

Medizin I, Universitätsklinikum Tübingen,

72076 Tübingen, Germany

Fax: +49-7071-2925034

martin.goetz@med.uni-tuebingen.de 